\title{
On the apparent viscosity of granular soils during liquefaction tests
}

\author{
Stefania Lirer ${ }^{a} \&$ Lucia Mele $^{b^{*}}$ \\ ${ }^{a}$ University Guglielmo Marconi, Roma, Italy \\ ${ }^{\mathrm{b}}$ University of Napoli Federico II, Italy \\ * corresponding author: lucia.mele@unina.it
}

\begin{abstract}
:
Liquefaction is a phenomenon marked by a rapid loss of soil strength and stiffness, which generally occurs in loose saturated sandy deposit during earthquake because of the generation of excess pore water pressure.Several experimental researches concluded that liquefied soil behaves as a fluid during ground movement, but after the earthquake motion ceases, due to the dissipation of excess pore water pressure and soil dilatancy, the liquefied soil recovers its initial stiffness and returns to behave as a solid.

Such a change of state can be analysed by considering the soil as an equivalent visco-plastic material, characterized by an apparent viscosity $(\eta)$ that changes during the cyclic loading. Following this approach, the authors analysed the results of some cyclic undrained triaxial tests carried out on reconstituted and undisturbed (frozen) specimens of sandy and gravelly soils in terms of apparent viscosity decay law $\left(\eta-N_{c y c}\right)$, highlighting the relevance of $\eta$ as physically based parameter for the correct identification of the liquefaction triggering. The experimental results confirm that the apparent viscosity decreases with the increase of the shear strain rate and highlight that the flow characteristics of liquefied soils (consistency coefficient and liquidity index) are affected by both grain size distributions and soil state condition (relative density and confining stress).
\end{abstract}

Keywords (max 5): soil liquefaction, apparent viscosity, undrained cyclic triaxial tests

\section{INTRODUCTION}

Liquefaction is a term used to describe a wide range of phenomena, marked by a rapid loss of soil strength or by an accumulation of plastic strains, which can occur in saturated cohesionless deposits during earthquake shaking - or other forms of rapid loading - because of the generation of excess pore water pressures. When liquefaction occurs, the effective stresses approach zero and soil behaviour switches from that of a solid to that of a liquefied state, causing serious damage to engineering structures.

Liquefaction mechanisms have been extensively studied through laboratory devices that can reproduce, in a simplified way, the in-situ stress conditions during earthquakes (Finn et al. 1971; Silver et al. 1980; Da Fonseca et al. 2015; Mele et al. 2019). Even though only the multi-directional simple shear tests (Ishihara and Yamazaki, 1980; Kammerer et al., 2004; Li et al. 2016) and true triaxial tests apparatus (Yamadaand Ishihara, 1983) can attempt to this requirement, conventional isotropically consolidated undrained cyclic triaxial tests are largely adopted by many researchers in the study of the soilliquefaction strength. The results are usually reported in the CSR-N $\mathrm{N}_{\text {cyc }}$ plane, where CSR is the Cyclic Stress Ratio, defined as:

$$
\operatorname{CSR}=\frac{q_{d}}{2 \cdot \sigma^{\prime}}
$$

Where $\mathrm{q}_{\mathrm{d}}$ is the cyclic deviatoric stress $\left(\mathrm{q}=\sigma_{1}-\sigma_{\mathrm{c}}\right)$ applied for a number of constant amplitude stress cycles $\mathrm{N}_{\mathrm{cyc}}$ and $\sigma_{\mathrm{c}}^{\prime}$ is the effective consolidation stress.

Defining $\mathrm{N}_{\text {liq }}$ as the value of $\mathrm{N}_{\text {cyc }}$ needed to reach liquefaction for a given value of CSR, the Cyclic Resistance Ratio (CRR) can also identified as the applied cyclic stress ratio for which $\mathrm{N}_{\text {cyc }}=\mathrm{N}_{\text {liq. }}$. The obtained curve in the plane CRR- $\mathrm{N}_{\text {liq }}$ identifies the soil Cyclic Resistance Curve, which depends on grain size distribution, soil fabric, state condition and degree of saturation (Verdugo and Ishihara, 1996; Huang et al., 2004; Mele et al, 2018). 
The cyclic resistance curve is strictly connected to the choice of the liquefaction triggering criterion (which rules the $\mathrm{N}_{\text {liq }}$ identification). The most used criteria are based on excess pore water pressure $(\Delta \mathrm{u})$ and strains measurements (axial strain $\varepsilon$ in triaxial tests and shear strain $\gamma$ in simple shear tests).

According to pore water pressure based criteria, liquefaction occurs when the excess pore pressure ratio $\left(r_{u}\right)$ is equal to 1.0 , where $r_{u}$ is defined as the ratio between the excess pore water pressure $(\Delta u)$ and the effective confining stress $\left(\sigma_{c}{ }_{c}\right)$. Ishihara (1993) suggestedfor soils containing some amounts of fines (silty sands and sandy silts) using a threshold of $r_{u}$ equal to about 0.90 to 0.95 .

Regarding to the strain criteria, it has some issues because the measurement of strains depends on deformation mode that the soil is subjected to, such as $\varepsilon_{\mathrm{DA}}$ (axial strain in double amplitude) in triaxial tests and shear strain $\Upsilon_{\mathrm{DA}}$ (shear strain in double amplitude) in simple shear tests. Another limitation is due to relative density $\left(D_{r}\right)$ of sandy soils, actually in loose sands the development of state of initial liquefaction $\left(\mathrm{r}_{\mathrm{u}} \approx\right.$ 1) is followed by accumulation of large strains, on the contrary in denser sands the attainment of initial liquefaction does not correspond to large strain owing to a strong dilatative behaviour (Wu et al., 2004). Ishihara (1993) proposed to use a threshold of $\varepsilon_{\mathrm{DA}}$ in cyclic triaxial tests equal to $5 \%$, other researchers use different strain levels.

From a mechanical point of view, when liquefaction fully develops the soil state has to change, passing from that of a granular medium to that typical of fluid. The Committee on Soil Dynamics of the Geotechnical Engineering Division of ASCE (1978) defined liquefaction as: "the act or process of transforming any substance into a liquid". This definition, apparently suggests a new triggering criterion based on the behaviour and the rheological properties of fluids.

Different researchers have developed numerical methods to study the behaviour of liquefied soil treating it as a solid with reduced stiffness and strength or as a fluid (Aydan, 1995; Uzuoka et al., 1998; Hadush et al., 2000; Hwang et al., 2006; Chen\& Liu 2011). Hamadaand Wakamatsu (1998) investigated the behaviour of liquefied soil during ground flow using several studies and experiments and concluded that liquefied soil behaves as a pseudoplastic fluid during ground movement, but after the earthquake motion ceases, the liquefied soil recovers its initial stiffness and returns to behave as a solid.

Some researches prefer to adopt the constitutive models of fluid mechanic to simulate and predict large deformation as lateral spreading (Uzuoka et al., 1998; Chen et al. 2011) or drag forces induced by liquefied soils on structures (Hamada, 2000).

Chen et al. (2006) analysed the main flow characteristics of liquefied sand by means of hollow torsion-shear tests: the experimental results showed that the constitutive model of the shear thinning non-Newtonian fluid (pseudo-plastic fluid) is able to reproduce the stress-strain rate relationship of the liquefied soils (Fig.1). The original flow constitutive model proposed by Chen et al. (2006) was later implemented into the finite difference algorithm FLAC3D (Chen et al. 2011) to reproduce the flow deformation process induced by soil liquefaction.

The constitutive model developed by Chen et al. (2006) considers that a liquefied sand, in zero effective stress condition, behaves as a pseudo-plastic fluid governed by the following relationship between the shear stress $(\tau)$ and the shear strain rate $(\dot{\gamma})$ :

$$
\tau=k \cdot(\dot{\gamma})^{n}
$$

where $\mathrm{k}$ and $\mathrm{n}$ are respectively the fluid consistency coefficient and liquidity index $(\mathrm{n}<1$ for shear thinning non Newtonian fluid; Zhou et al., 2014).

The expression of the " viscosity of liquefied soil" can be derived as:

$$
\eta=\frac{\tau}{\dot{\gamma}}=k \cdot(\dot{\gamma})^{(n-1)}
$$

The constitutive model parameters ( $\mathrm{k}$ and $\mathrm{n}$ ) must be calibrated on experimental results, but very few data are available in literature, and generally they refer to reconstituted uniform sandy soils.

In this paper the results of many cyclic undrained triaxial tests will be processed with the fluid mechanics approach, by considering tested soils as equivalent viscous materials, characterized by an "apparent 
viscosity" decay law. The triaxial tests have been carried out by the authors on reconstituted and undisturbed cohesionless soils, with grain size distributions ranging from fine grained sands to well graded gravelly materials.

The suitability of the eq. (2) was verified on these experimental results and the parameter $\mathrm{k}$ and $\mathrm{n}$ have been calibrated for the tested materials and test conditions.



Figure 1. Shear stress - shear strain rate relation for non-Newtonian fluid

\section{MATERIALS AND CYCLIC BEHAVIOUR}

\subsection{Tested materials}

In order to analyse the undrained cyclic behaviour of cohesionless soils, two different materials have been considered: a gravelly soil coming from south Italy (Messina Strait, Sicily) and a sandy soil coming from northern Italy (Sant'Agostino, Ferrara). In the following, for brevity, Sant'Agostino sand will be indicated using the acronym SAS. Both soils have been deeply studied by the authors in previous works (Flora et al., 2012; Flora \&Lirer, 2013; Mele et al., 2018). Their grain size distributions and main physical and mechanical properties are reported in Fig. 2. The gravelly soils have gradings range from uniform sand (MES-A, Fig. 2a) with a very low percentage of gravel to well-graded sandy gravel (MES-C, Fig. 2a).

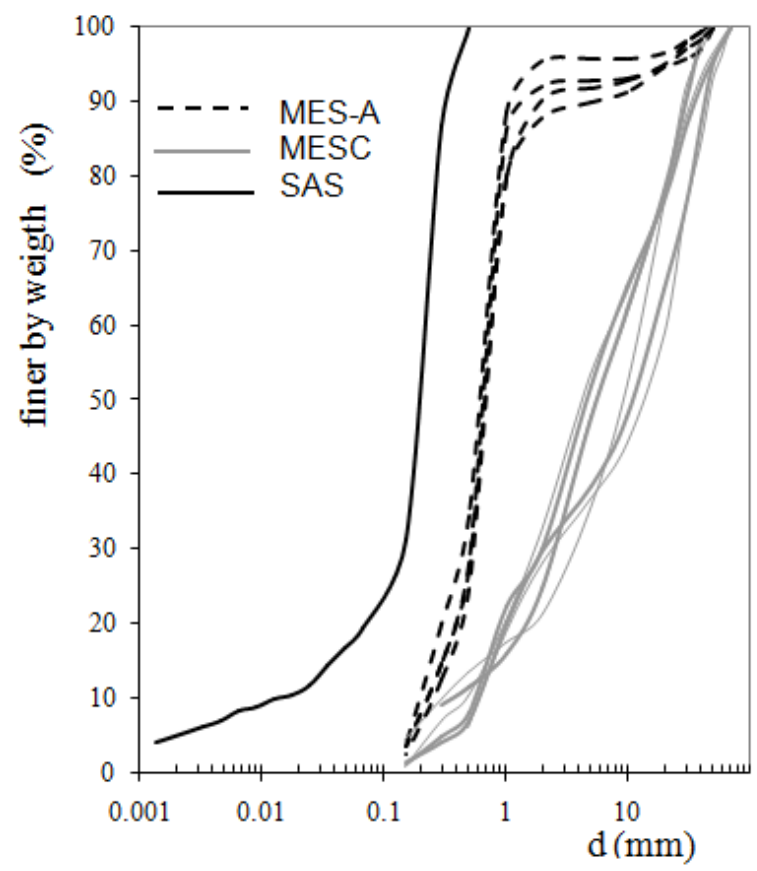

\begin{tabular}{|c|c|c|c|c|}
\hline Soil & $\begin{array}{c}\mathrm{D}_{50} \\
(\mathrm{~mm})\end{array}$ & $\mathrm{C}_{\mathrm{u}}$ & Gs & $\begin{array}{c}\varphi_{\mathrm{u}}{ }^{*} \\
\left({ }^{\circ}\right)\end{array}$ \\
\hline MES-A & 0.7 & 2.8 & \multirow{2}{*}{2.70} & 38.6 \\
\cline { 1 - 3 } \cline { 5 - 5 } MES-C & 10 & 26 & & 43.2 \\
\hline SAS & 0.2 & 16.7 & 2.67 & 32.5 \\
\hline
\end{tabular}

Figure 2. Gradings of tested soil sand, their main physical and mechanical properties 


\subsection{Liquefaction strength of tested materials}

\subsubsection{Messina gravelly soils}

Undisturbed large size undisturbed samples were recovered on the Calabrian shore of the Messina Strait (Cannitello site) at depths ranging between 18 to $33 \mathrm{~m}$, in the so-called Coastal Deposits geological formation. Coastal Deposits are recent, normally consolidated coarse-grained soils deposited in the Holocene age $\left(35<\mathrm{D}_{\mathrm{r} 0}<50 \%\right.$, Callisto et al., 2013). Due to their large particles, these soils have been tested in a large triaxial apparatus (specimen diameter $\mathrm{D}=20 \mathrm{~cm}$, specimen height $\mathrm{H}=40 \mathrm{~cm}$ ) developed at the University of Napoli Federico II. In all tests, the thawing of the specimens took about 24 hours, and was carried out in the triaxial cell imposing a low isotropic effective stress $\left(\sigma^{\prime}{ }_{c}=20 \mathrm{kPa}\right)$ in drained conditions, with a back pressure of $30 \mathrm{kPa}$. Consistently with the indications of Tanaka et al. (1991), in all cases it was experimentally observed that the effects of membrane penetration during thawing were negligible (Flora et al., 2012). Upon thawing, saturation was guaranteed by water flow under a very low hydraulic gradient. In all cyclic tests, the axial loading was applied through uniform sinusoidal cycles with constant amplitude at a frequency of 0.1 Hz. The isotropically consolidated undrained cyclic tests (CCIU) were carried out with symmetrical cycles with respect to the $\mathrm{q}=0$ (isotropic) axis, thus resulting in a cyclic inversion of major and minor principal effective stresses.

A synthesis of the undrained cyclic test results is reported in Table 1. For each applied CSR, the value of $\mathrm{N}_{\text {liq }}$ was computed with both stress $\left(r_{u}=0.9\right)$ and strain based criteria (a conservative value has been chosen for the double amplitude axial strain, $\varepsilon_{\mathrm{DA}}=2.5 \%$ ). It can be noted that the two criteria gave generally similar results for the uniform sandy soil (MES-A), while for the well graded sandy gravel (MES-C), some differences have been sometimes observed.

In Fig. 3 the results of CCIU tests on MES-C are plotted in the traditional cyclic resistance plane, CRR: $\mathrm{N}_{\text {liq }}\left(\mathrm{r}_{\mathrm{u}}\right)$.To express the dependency of the cyclic resistance curve on the soil density and confining stress, the data points have been grouped in set of samples with comparable values of the well-known state parameter $\psi$ (Jefferies\& Been, 2006) computed after consolidation and prior to undrained cyclic loading.

Table 1. Undrained cyclic tests carried out on undisturbed specimens of Messina gravelly soils.

\begin{tabular}{|c|c|c|c|c|c|c|c|}
\hline Soil & Test & $\sigma_{\mathrm{c}}^{\prime}(\mathrm{kPa})$ & $\mathrm{e}^{*}$ & $\psi$ & CSR & $\mathrm{N}_{\mathrm{liq}}\left(\varepsilon_{\mathrm{DA}}\right)$ & $\mathrm{N}_{\mathrm{liq}}\left(\mathrm{r}_{\mathrm{u}}\right)$ \\
\hline \multirow{5}{*}{ MES-A } & $1 \mathrm{~A}$ & \multirow{5}{*}{200} & 0.659 & -0.183 & 0.313 & 2 & 2 \\
\hline & $2 \mathrm{~A}$ & & 0.761 & -0.076 & 0.200 & 24 & 24 \\
\hline & $3 \mathrm{~A}$ & & 0.756 & -0.082 & 0.270 & 4 & 3 \\
\hline & $4 \mathrm{~A}$ & & 0.562 & -0.200 & 0.250 & 24 & 22.5 \\
\hline & $5 \mathrm{~A}$ & & 0.610 & -0.230 & 0.230 & 32 & 35 \\
\hline \multirow{4}{*}{ MES-C } & $1 \mathrm{C}$ & 200 & 0.538 & -0.125 & 0.265 & 12 & 12 \\
\hline & $2 \mathrm{C}$ & 200 & 0.462 & -0.196 & 0.326 & 6 & - \\
\hline & $3 C$ & 400 & 0.483 & -0.086 & 0.357 & 5 & 3.5 \\
\hline & $6 \mathrm{C}$ & 200 & 0.557 & -0.100 & 0.220 & 47 & 53 \\
\hline
\end{tabular}

*at the end of consolidation phase 


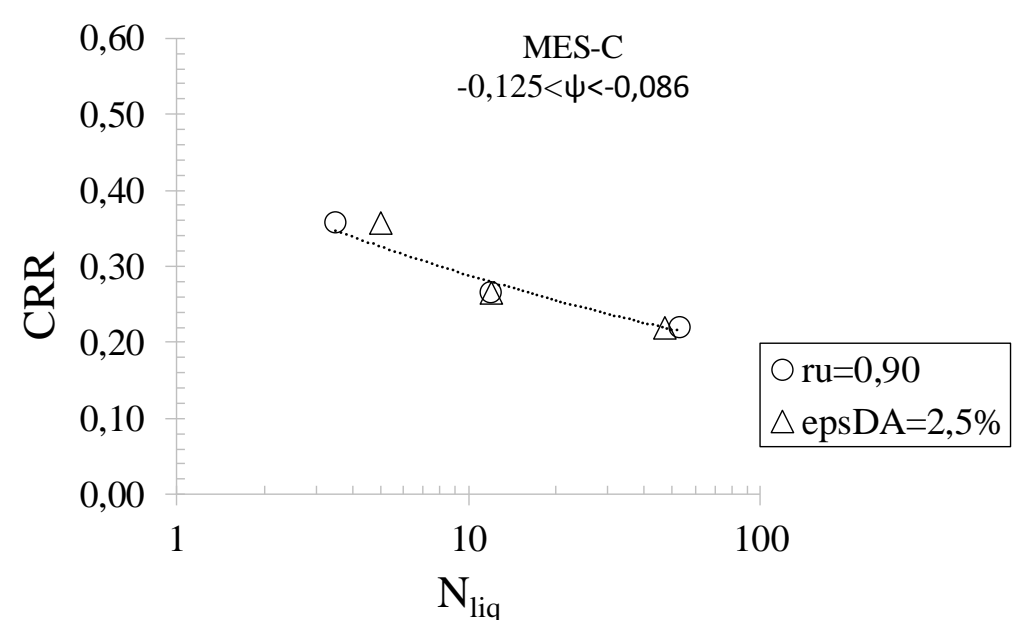

Figure3. Cyclic resistance curve of the specimens MES-C (Tab.1)

\subsubsection{Sant'Agostino Sand}

Sant'Agostino sand comes from an area (Sant'Agostino, Ferrara, Italy) located in Emilia Romagna region, which was affected by extensive liquefaction phenomena during the 2012 earthquake. The soil was retrieved at a depth between $6.8-8.0 \mathrm{~m}$ from the ground level. Mele et al. (2018) performed seven undrained cyclic triaxial tests (Tab. 2) on fully saturated specimens reconstituted - by wet pluviation- at two different relative densities $\left(D_{r}=46\right.$ and $\left.60 \%\right)$. In this research, other three tests on specimens prepared at higher value of $D_{r}$ $\left(D_{r}=74 \%\right)$ were added. All tests were carried out in a Bishop \& Wesley triaxial cell on specimens having diameter of $38 \mathrm{~mm}$ and height of $76 \mathrm{~mm}$. The saturation phase was obtained in the TX apparatus imposing a low isotropic confining effective stress of $10 \mathrm{kPa}$ in drained conditions. After the saturation phase, the specimens were isotropically consolidated at a confining stress $\left(\sigma^{\prime}{ }_{\mathrm{c}}\right)$ of $50 \mathrm{kPa}$ and then the axial loading was applied through uniform sinusoidal cycles with constant amplitude at a frequency of $0.008 \mathrm{~Hz}$.

Table 1: Undrained cyclic tests carried out on specimens of Sant'Agostino sand.

\begin{tabular}{|c|c|c|c|c|c|c|}
\hline Test & $\sigma_{\mathrm{c}}^{\prime}(\mathrm{kPa})$ & $\mathrm{e}^{* * *}$ & Dr** $(\%)$ & CSR & $\mathrm{N}_{\text {liq }}\left(\varepsilon_{\mathrm{DA}}\right)$ & $\mathrm{N}_{\mathrm{liq}}\left(\mathrm{r}_{\mathrm{u}}\right)$ \\
\hline S_SA1* & 50 & 0.707 & 47 & 0.147 & 2.7 & 3 \\
\hline S_SA2* & 50 & 0.738 & 43 & 0.128 & 7.5 & 7 \\
\hline S_SA3* & 50 & 0.719 & 46 & 0.098 & 19 & 19 \\
\hline S_SA4* & 50 & 0.713 & 47 & 0.087 & No & No \\
\hline S_SA5* & 50 & 0.604 & 64 & 0.179 & 3 & 3 \\
\hline S_SA6* & 50 & 0.636 & 59 & 0.147 & 13 & 11.5 \\
\hline S_SA7* & 50 & 0.652 & 56 & 0.128 & 15.5 & 14 \\
\hline S_SA8 & 50 & 0.536 & 74 & 0.198 & 8 & 4 \\
\hline S_SA9 & 50 & 0.524 & 75 & 0.179 & - & 9 \\
\hline S_SA10 & 50 & 0.542 & 73 & 0.164 & 41 & 28 \\
\hline
\end{tabular}

*Mele et al. (2018); **at the end of consolidation phase

In Figure 4 the results of the cyclic tests have been plotted in the traditional plane CRR $-\mathrm{N}_{\text {liq }}$, where $\mathrm{N}_{\text {liq }}$ was computed with both triggering criteria (Tab. 2). As mentioned before, for loose specimens $\left(D_{\mathrm{r}}=46 \%\right)$ thestress and strain criteria give the same results, while it does not happen for the dense ones $\left(\mathrm{D}_{\mathrm{r}}=60 \%\right.$ and 74\%). For these specimens the pore pressure build-up is not followed by an accumulation of large strains, owing to a more dilating soil behaviour. 


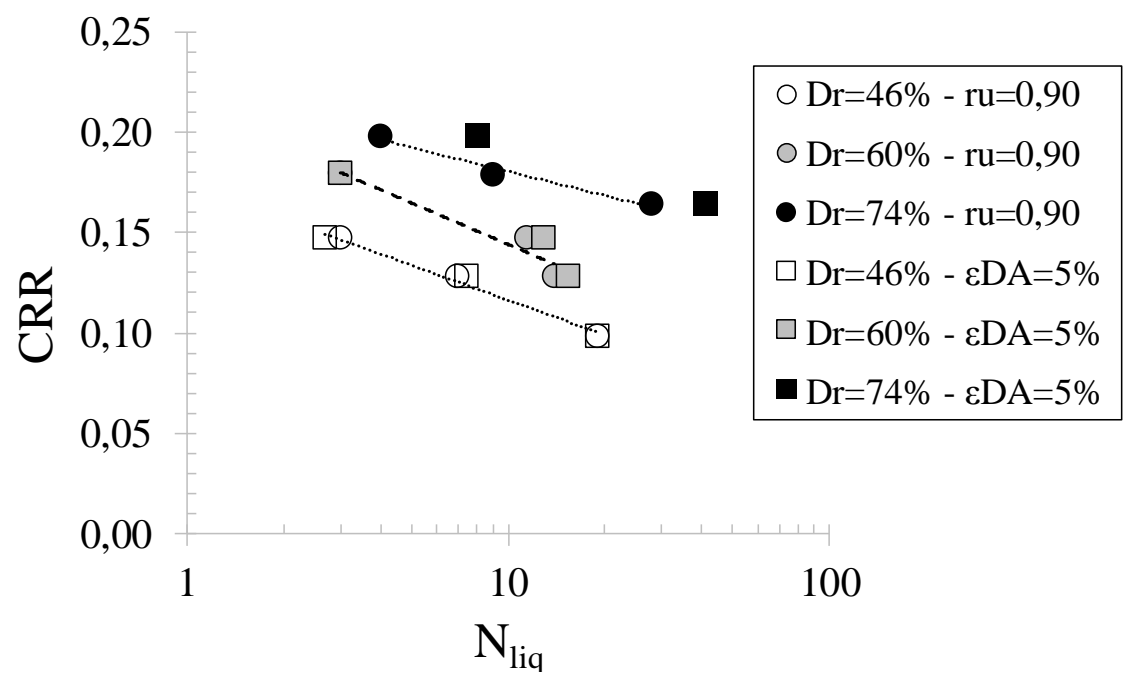

Figure4. Cyclic resistance curves of Sant'Agostino sand for different values of relative density $\mathrm{D}_{\mathrm{r}}$ (Tab.2)

\section{APPARENT VISCOSITY MEASUREMENTS}

The stress-strain response of a soil undergoing cyclic loads (i) can be processed in the framework of fluids mechanic, computing an "apparent viscosity" defined as (Chen et al., 2016):

$$
\eta_{i}=\frac{\tau_{i, \max }-\tau_{i, \min }}{\dot{\gamma}_{i, \max }-\dot{\gamma}_{i, \min }}
$$

Where $\tau_{\max }$ and $\tau_{\min }$ are the maximum and minimum values of the applied cyclic shear stress and $\dot{\gamma}_{\text {max }}$ and $\dot{\gamma}_{\text {min }}$ are the of the shear strain rates.

Starting from the cycles stress - strain of cyclic triaxial tests, the apparent viscosity can be calculated also from cyclic triaxial tests results, easily converting the cyclic deviatoric stress (q) and the corresponding axial strain $\left(\varepsilon_{a}\right)$ in the shear stress acting on the plane inclined at $45^{\circ}$ on the horizontal plane $(\tau=q / 2)$ and in the corresponding shear strain $(\gamma=1.5 \varepsilon)$.

Figures 5 show two examples of the experimental relationships between deviatoric stress and axial strain (Figs.5(a) and (b)) and also the cycles in the plan shear stress versus shear strain rates (Figs. 5(c) and (d)): both figures illustrate that after the first cycles ( 2 cycles for test SA5* and 3 cycles for test $3 \mathrm{~A}$ ), the values ofthe deviatoric strain rate $\dot{\gamma}$ (max and min) increase with $\mathrm{N}_{\text {cyc }}$ and, as a consequence, the enclosed area of the stress-strain rate loop gradually increases, and then the energy dissipation rate increase gradually with $\mathrm{N}_{\mathrm{cyc}}$. 


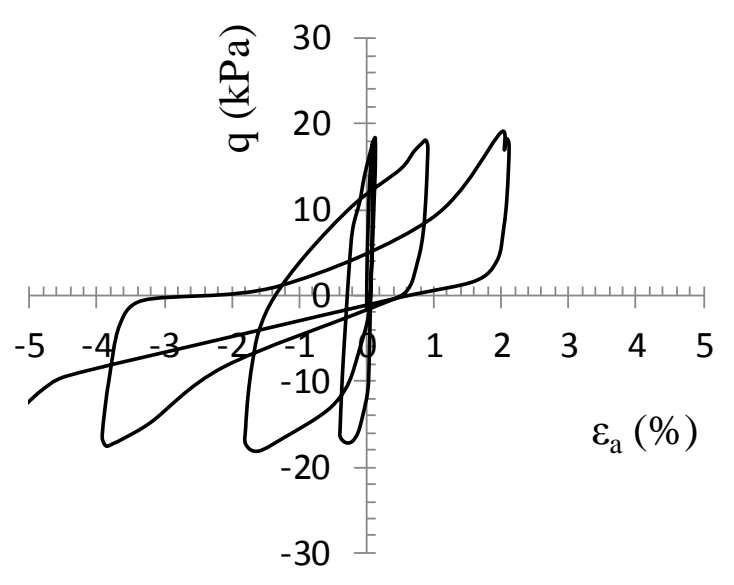

(a)



S_SA5*



(b)

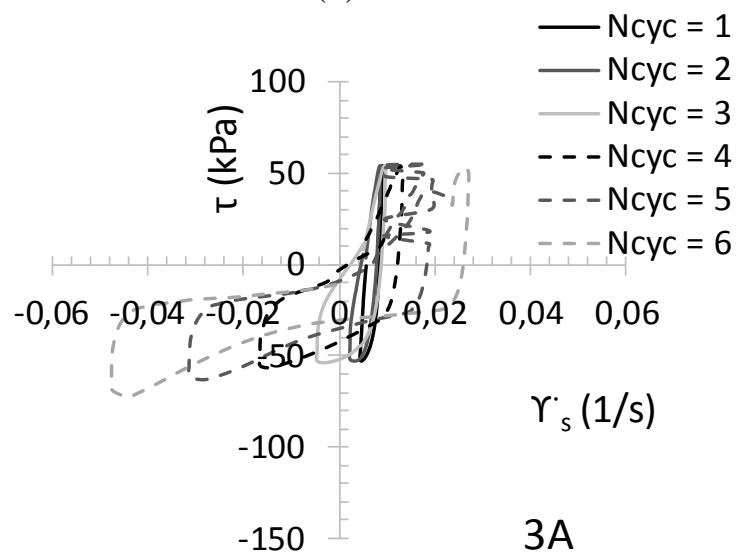

(d)

Figure 5. Deviatoric stress versus axial strain for S_SA5* test (a) and 3A test (b)and shear stress $(\tau)$ versus the shear strain rates $\gamma$ for S_SA5* test (c) and 3A test (d)

For each stress-strain rate loop (Figs.5c and $5 \mathrm{~d}$ ), a single value of the apparent viscosity, the diagonal line slope of $\tau-\dot{\gamma}$, can be computed via eq. (4).

The decay laws of $\eta$ with the number of cycles $\mathrm{N}_{\text {cyc }}$ are plotted in Figs. 6 for all the triaxial tests (Figs. 6a, for SAS specimens and Figs.6b for MES specimens). The same results have been also plotted in semilogarithmic plane in Fig. 7, in order to make more clear the minimun value reached by $\eta$ at the end of the tests, when fully liquefaction was attained.

As previously mentioned, in each test the apparent viscosity decreases as the number of cycles $\mathrm{N}_{\text {cyc }}$ increases. The apparent viscosity decay law $\eta-\mathrm{N}_{\text {cyc }}$ is mainly affected by the applied CSR but less significantly by the confining stress and initial relative density. The form of the decay law is more clear for tests where the liquefaction is attained in many cycles $\left(\mathrm{N}_{\text {liq }}>10\right)$ : in these cases it can be noted that in the first part of the loading process, the apparent viscosity slightly decreases. After that, a sudden, sharp decrease of $\eta$ is experimentally observed until a minimum value is attained. This value, called $\eta_{\text {fluid }}$ by Mele et al. (2018), may identify the condition of full liquefaction, when the soil is turned in a fluid.

The experimental results (Figs. 6-7) indicate that the initial value of $\eta\left(\eta_{0}\right)$ do not dependent on soil state $\left(D_{r}\right.$ and confining pressure), but only on particles size. In Fig. 8, the average values of $\eta_{0}$ computed for each tested soil (SAS, MES-A, MES-C) have been plotted versus $\mathrm{D}_{50}: \eta_{0}$ increases with $\mathrm{D}_{50}$ according to a power function, whose expression is reported in Fig. 8. The arrows in Fig. 8 indicate the dispersion of the experimental data.

While the initial value of $\eta\left(\eta_{0}\right)$ does not depend on state of soil, but only on particles size, the final value $\left(\eta_{\text {fluid }}\right)$ depends on the state of the soil, as shown in Figs. 7a,b,c. For SAS tests the final value of $\eta$ can be assumed equal to $0.3,0.6$ and $2 \mathrm{MPa} \cdot \mathrm{s}$ respectively for the average $\mathrm{D}_{\mathrm{r}}$ of 46,60 and $74 \%$. Also confining 
pressure can affect $\eta_{\text {fluid. }}$ It can easily understand looking at the Fig. $7 \mathrm{~d}$. Apart from the test $3 \mathrm{C}\left(\sigma_{\mathrm{c}}{ }_{\mathrm{c}}=\right.$ $400 \mathrm{kPa})$ where $\eta_{\text {fluid }}$ assumes a value of $20 \mathrm{MPa} \cdot \mathrm{s}$, for the other tests $\left(\sigma_{\mathrm{c}}=200 \mathrm{kPa}\right) \eta_{\text {fluid }}$ is $8 \mathrm{MPa} \cdot \mathrm{s}$.

As expecdet, $\eta_{\text {fluid }}$ is not affected by the applied CSR: when liquefaction is fully attained the soil behaves like a liquid and its properties are linked to properties of soil, regardless of the cyclic loading that bring it to attain liquefaction.

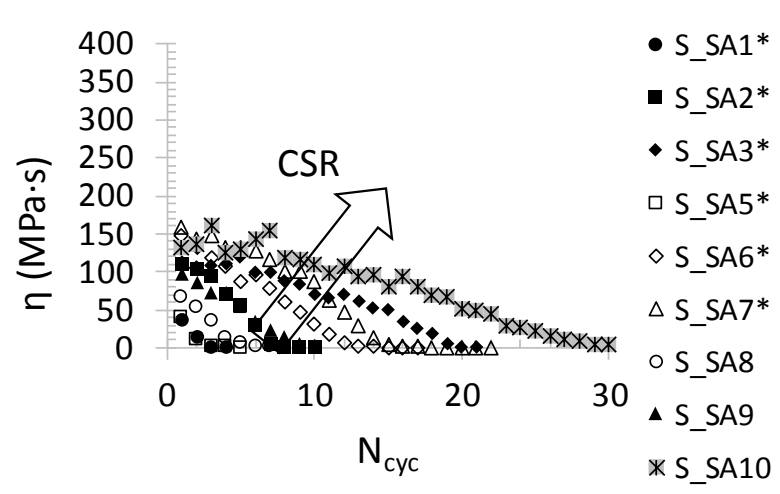

(a)

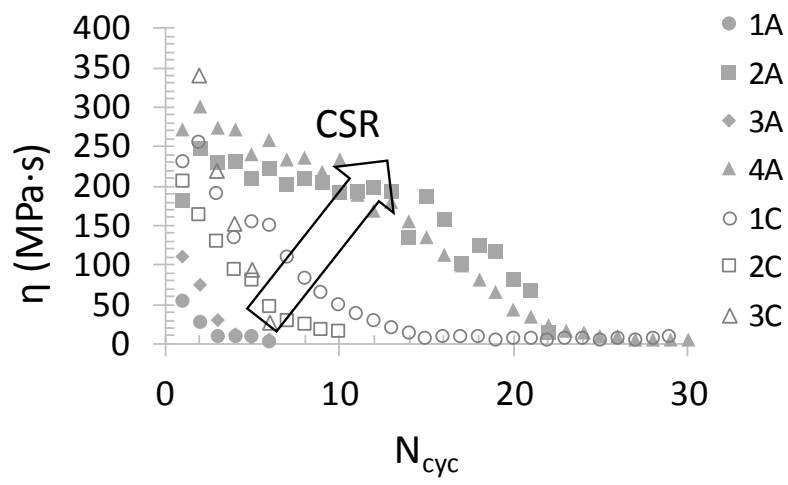

(b)

Figure 6. Apparent viscosity decay law measured in cyclic tests on SAS soil $\left(a, a_{1}\right)$ and MES soil (b, $\left.b_{1}\right)$.

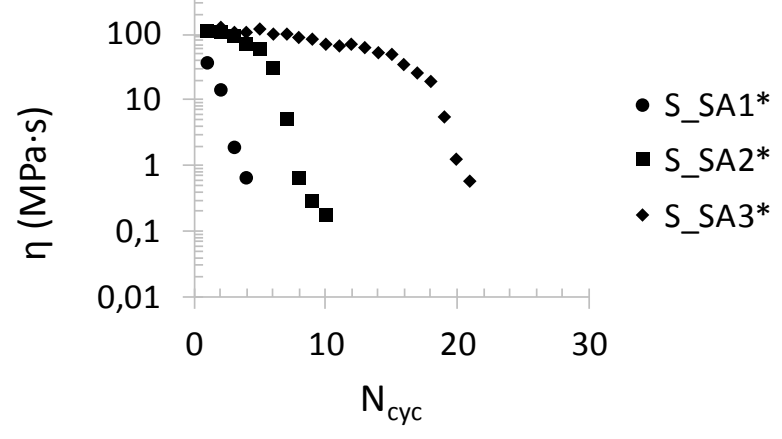

(a)

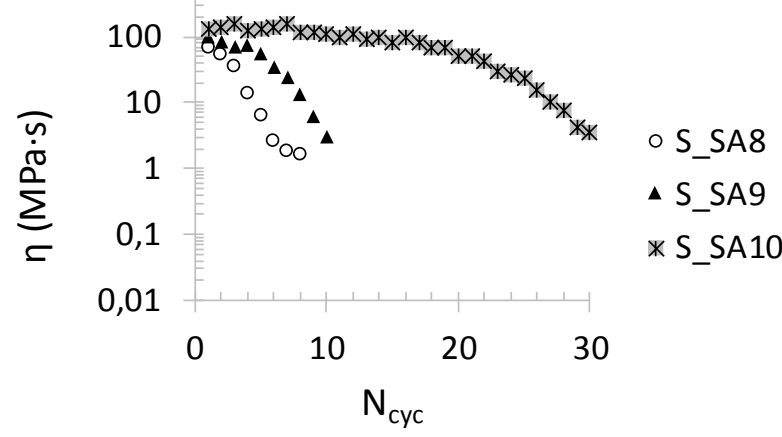

(c)

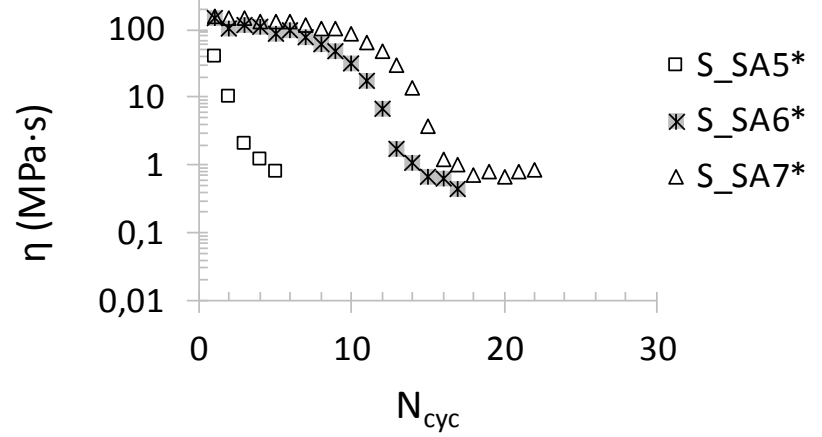

(b)

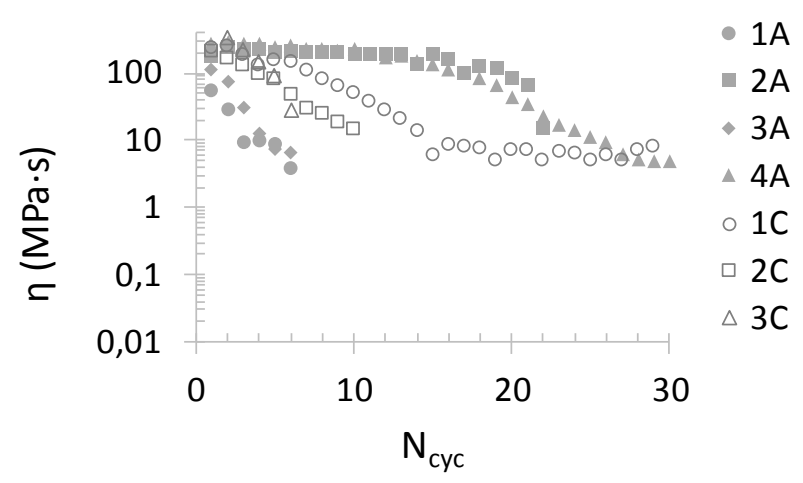

(d)

Figure 7. The effect of relative density on final value of viscosity ( $\eta_{\text {fluid }}$ ) for SAS tests: $\operatorname{Dr}=46 \%$ (a), $60 \%$ (b) and $74 \%$ (c); and the effect of confining stress on $\eta_{\text {fluid }}$ for Messina soils (d). 


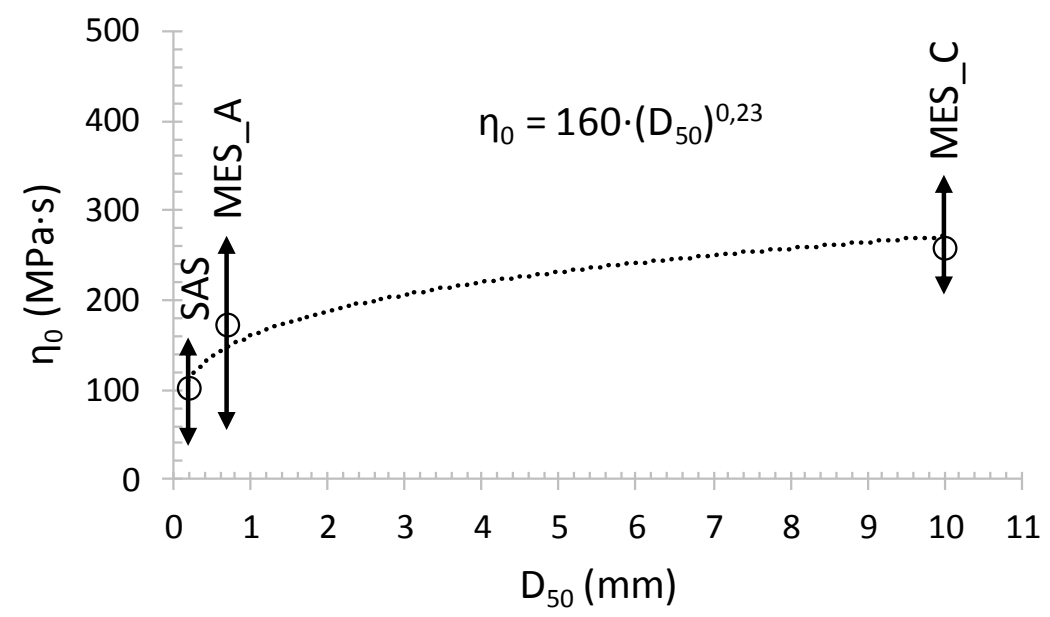

Figure 8. Initial apparent viscosity $\left(\eta_{0}\right)$ with $\mathrm{D}_{50}$ of the tested soils (SAS, MES-A, MES-C).

The values of apparent viscosity have been plotted versus the corresponding maximun value of the shear strain rate $\dot{\gamma}$ measured in the cycle in Fig. 9. The experimental results confirm that the values of $\eta$ decrease with increasing $\dot{\gamma}$ according to the correlation expressed by eq. (3). The best fitting parameters $\mathrm{k}$ and $\mathrm{n}$ (eq. 3) are plotted in Tab. 3. It can be noted that the parameter $\mathrm{k}$ (consistency coefficient) is affected by soil grading, relative density and confining stress. Regarding the parameter $\mathrm{n}$ (liquid index), it is always less than 1 and seems to be mainly affected by the relative density.

The values of the consistency coefficient $(\mathrm{k})$ computed for all the tests have been plotted in Fig. 10 versus the confining stress: the results of tests on SAS specimens confirm the linear relationship experimentally proposed by Zhou et al. (2014) for tests on sandy soilwith similar properties of $S A S\left(G_{s}=2.70 ; d_{50}=0.16 \mathrm{~mm}\right.$; $\mathrm{e}_{\max }=1.14$ and $\left.\mathrm{e}_{\min }=0.62\right)$ at a $\mathrm{Dr}=50 \%$. As expected, the values of $\mathrm{k}$ calculated by processing the tests on coarse soils (Messina) do not lie on the same line, confirming the dependence of this relationship on soil characteristics. The test performed on MES-C at high confining stress (400 kPa) was not reported in the plot because for these stress levels other tests are under course.

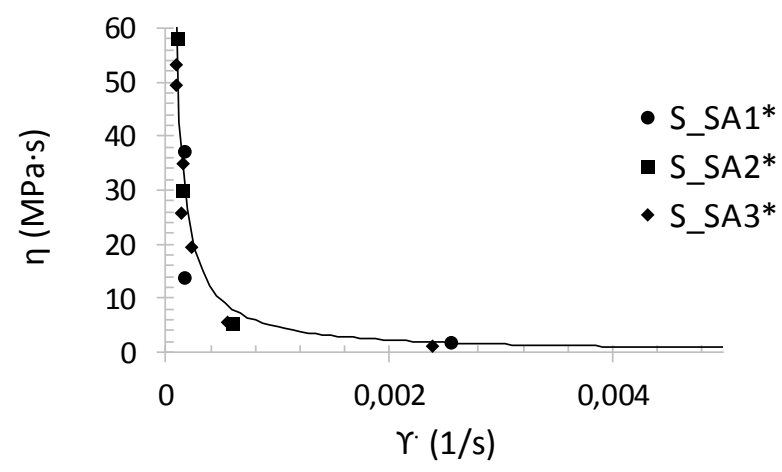

(a) SAS, $D_{r}=46 \%$



(b) MES-A, $\sigma_{c}^{\prime}=200 \mathrm{kPa}$ 


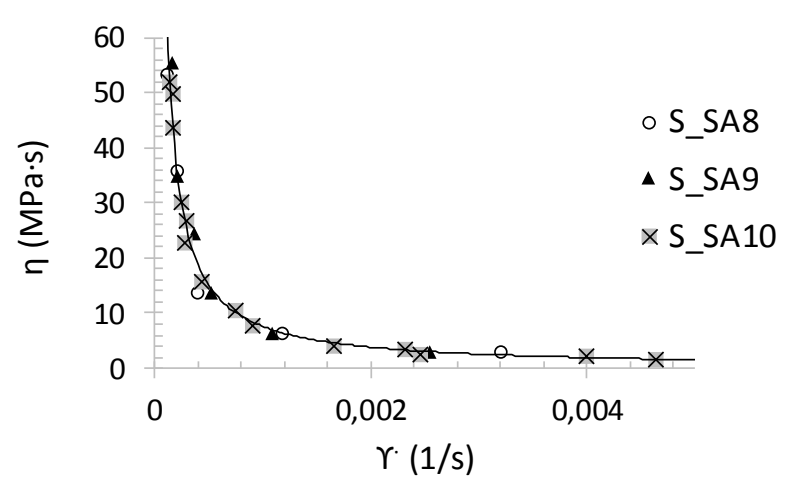

(c) SAS, $\mathrm{D}_{\mathrm{r}}=60 \%$

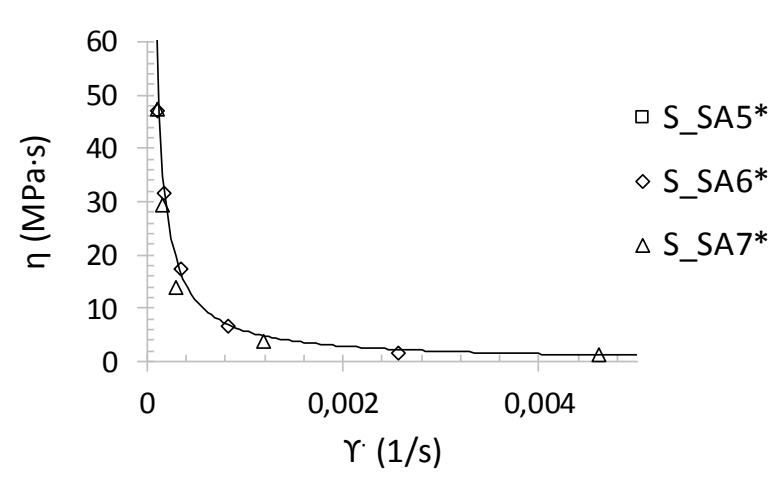

(e) $\mathrm{SAS}, \mathrm{D}_{\mathrm{r}}=74 \%$

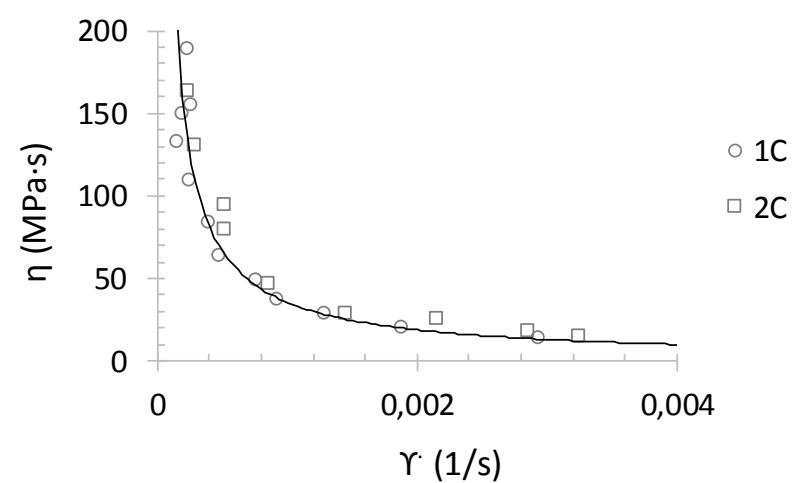

(d) MES- C, $\sigma_{c}^{\prime}=200 \mathrm{kPa}$

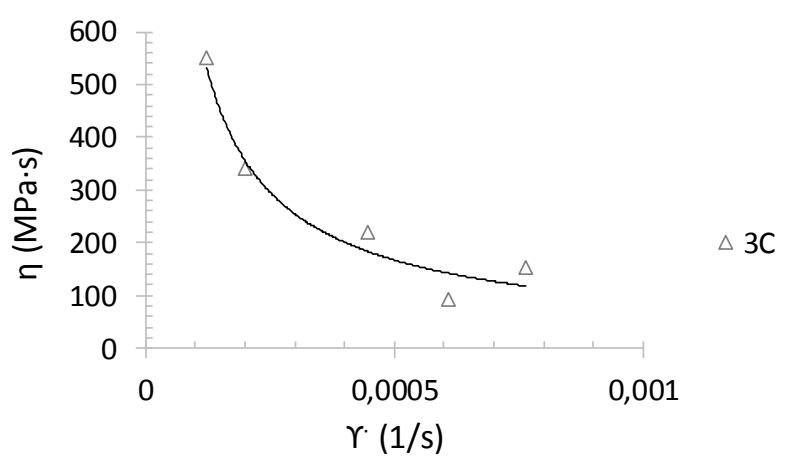

(f) MES- $\mathrm{C}, \sigma_{\mathrm{c}}^{\prime}=400 \mathrm{kPa}$

Figure 9. Apparent viscosity versus shear strain rate for cyclic tests on SAS soil with different relative densities (a; c and $e$ ) and MES soil (b, d and f).

Table 3. Best fittingparameters of eq. (3)

\begin{tabular}{|c|c|c|c|c|}
\hline Soil & $\begin{array}{c}\mathbf{D r} \\
(\boldsymbol{\%})\end{array}$ & $\begin{array}{c}\boldsymbol{\sigma}_{\mathbf{c}} \\
(\mathrm{kPa})\end{array}$ & consistency coefficient, $\mathbf{k}$ & liquid index, $\mathbf{n}$ \\
\hline SAS & 46 & 50 & 3.54 & -0.039 \\
\hline SAS & 60 & 50 & 6.07 & 0.007 \\
\hline SAS & 74 & 50 & 8.24 & 0.012 \\
\hline MES_A & - & 200 & 32.0 & -0.04 \\
\hline MES_C & - & 200 & 67.0 & 0.092 \\
\hline MES_C & - & 400 & 322.2 & 0.117 \\
\hline
\end{tabular}

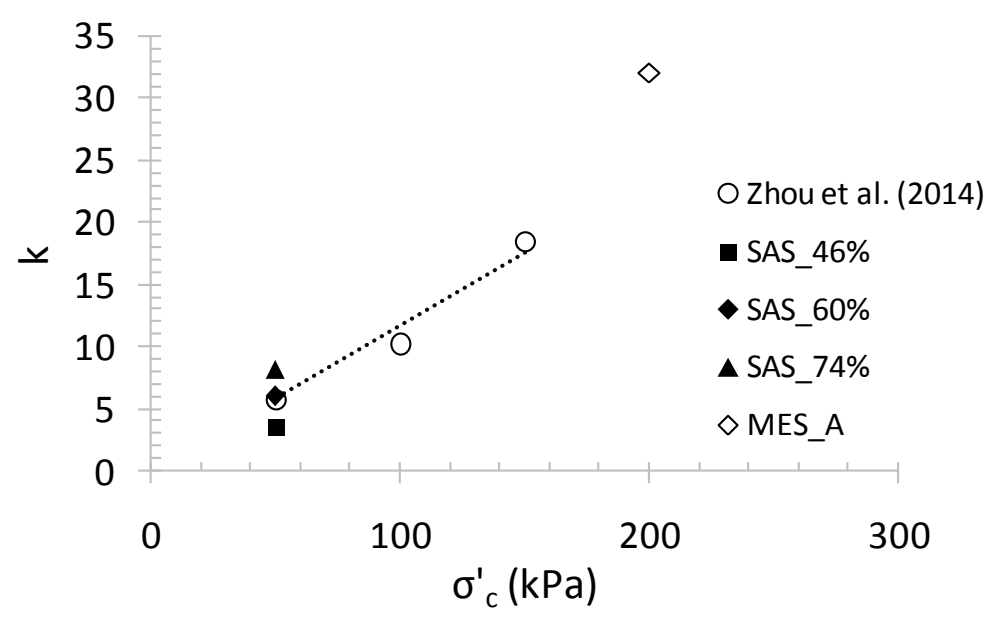

Figure 10. Consistency coefficient k (eq.3) for the tests carried out on SAS and MES_A specimens (Tab.3) 


\section{RELATIONSHIP BETWEEN APPARENT VISCOSITY AND PORE PRESSURE RATIO}

Considering that the apparent viscosity decay law (Figs.6) represents the change in soil state during liquefaction, it is reasonable to assume that such a law can be adopted as a liquefaction triggering criteria too. In order to verify this hypothesis, the results of some tests (S_SA2*; 4A; 1C and 3C; see Tab. 1) on Sant'Agostino sand and Messina gravelly soils (A and C) have been plotted, as an example, in the planes $\eta$ $\mathrm{N}_{\text {cyc }}-\mathrm{r}_{\mathrm{u}}$ (Fig. 11a-c-e-g).

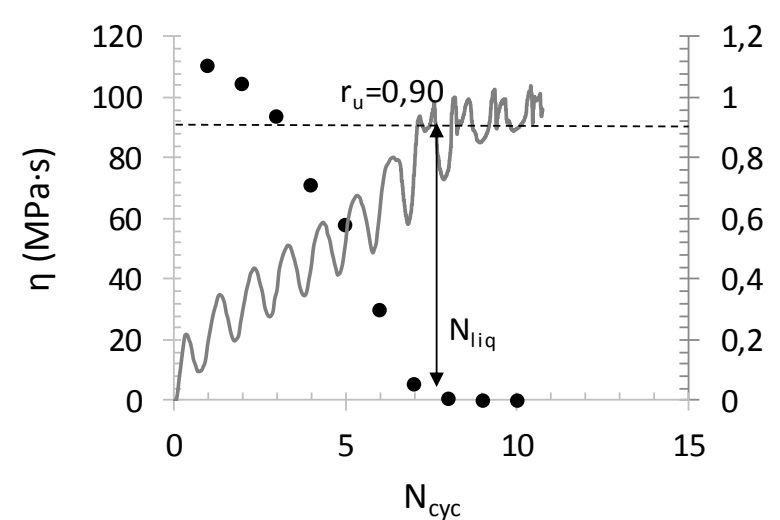

(a) S_SA2*

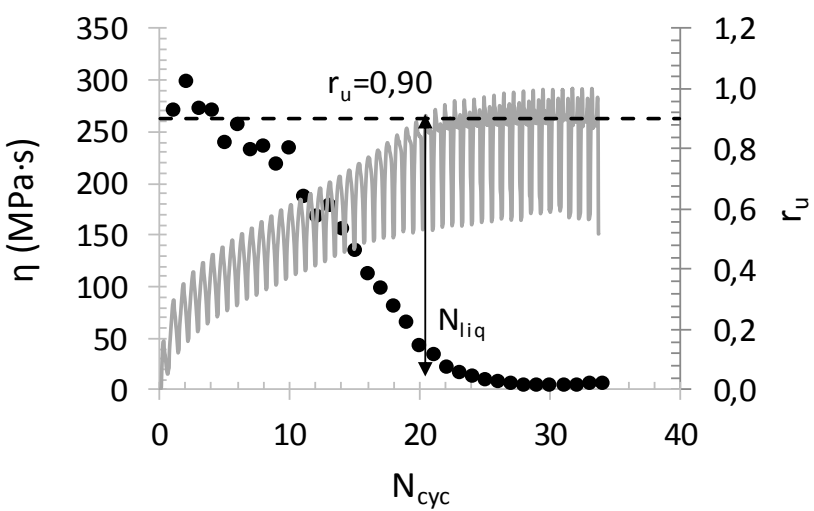

(c) $4 \mathrm{~A}$

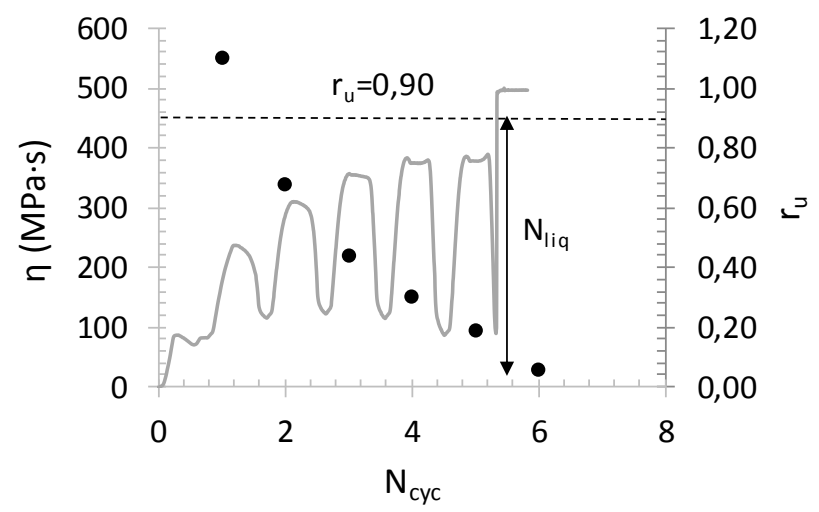

(e) $1 \mathrm{C}$

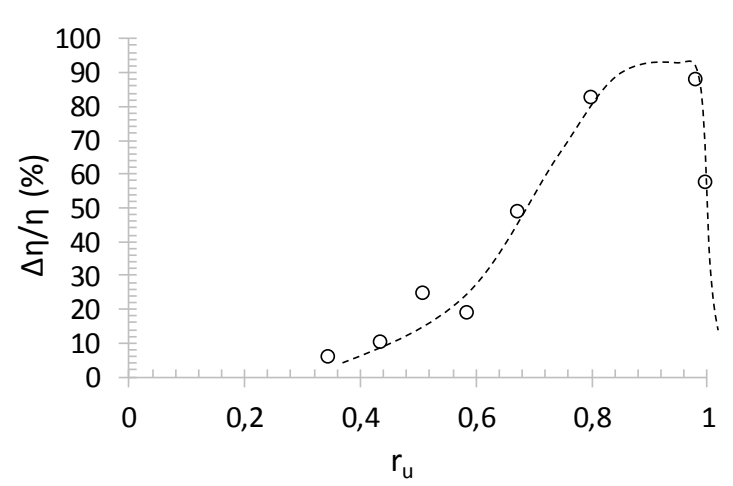

(b) S_SA2*

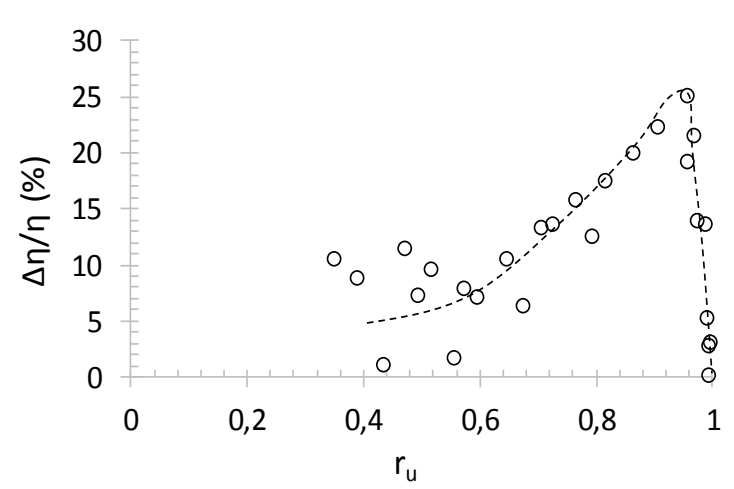

(d) $4 \mathrm{~A}$

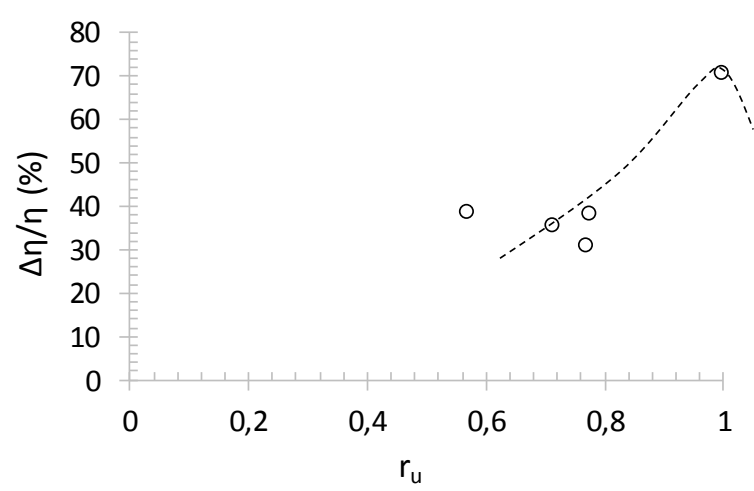

(f) $1 \mathrm{C}$ 


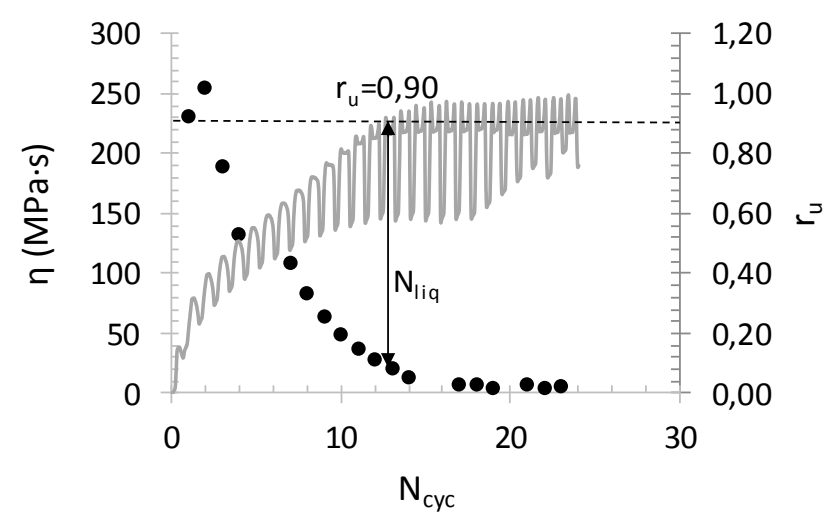

(g) $3 \mathrm{C}$

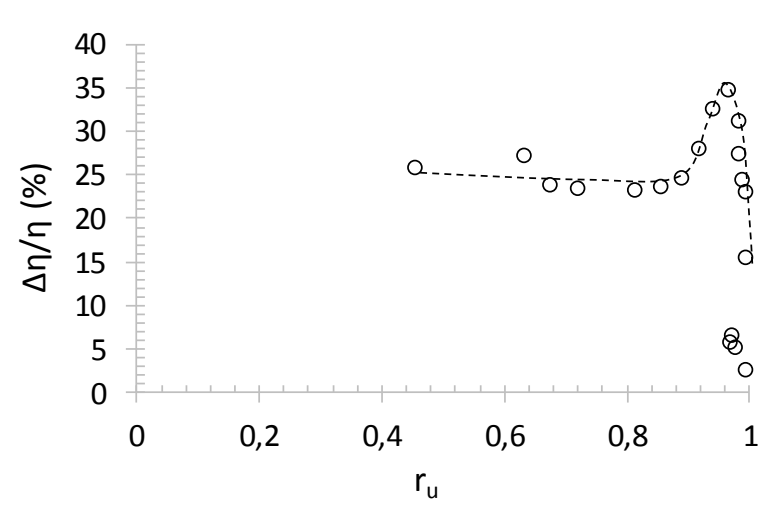

(h) $3 \mathrm{C}$

Figure 11. Results of some tests (S_SA2* (a-b); 4A (c-d); 1C (e-f) and 3C (g-h)) in terms of $\eta-\mathrm{N}_{\mathrm{cyc}}-\mathrm{r}_{\mathrm{u}}(\mathrm{a}-\mathrm{c}-\mathrm{e}-\mathrm{g})$ and $\Delta \eta / \eta-r_{u}(b-f-f-h)$

The results plotted in Fig. 11a reveal a strong link between the decay law of the apparent viscosity $\eta-\mathrm{N}_{\mathrm{cyc}}$ and the pore pressure ratio build up during the cyclic loading path: the value of $\eta$ decreases as the pore water pressure $r_{u}$ increases and the maximum gradient of the curvature (the elbow of the curve $\eta-\mathrm{N}_{\text {cyc }}$ ) is attained exactly at the pore pressure ratio threshold $\left(\mathrm{r}_{\mathrm{u}}=0.90\right)$. It can be expressed more clearly plotting the gradient of the curvature $(\Delta \eta / \eta)$ versus $r_{u}$ (Fig. 11b), where $\Delta \eta / \eta$ is evaluated as $\left(\eta_{i-} \eta_{i+1}\right) / \eta_{i}$.

The relationship $\Delta \eta / \eta-r_{u}$ may be described by a bell-shaped curve, whose maximum is attained when $r_{u}$ is 0.90. It confirms that the pore water pressure based criteria is a stronger way to identify the attainment of liquefaction than the strain based criteria, which depends on the choice of the operator. The attainment of liquefaction according to apparent viscosity is physically based because it considers the change of physical state of the soil during liquefaction.

This evidence leads to the definition of the conceptual framework sketched in Fig. 12, that highlights the relevance of $\eta$ as physically based parameter for the correct identification of the liquefaction triggering, intended as a change in soil state. For loading cycles far from liquefaction triggering, the soil is in a solid state and the initial value of $\eta\left(\eta_{0}\right)$ is quite constant. After that, the pore water pressure starts to increase and a "transition phase" can be identified in which the apparent viscosity suddenly decreases (in this phase the liquefaction triggering starts). At the end of the transition phase, the liquefaction fully develops $\left(r_{u}=0.90\right)$ and the complete change of state leads to a sudden collapse of the value of the apparent viscosity to a minimun value $\left(\eta=\eta_{\text {fluid }}\right)$. In this phase $\left(\eta=\eta_{\text {fluid }}\right)$, a rapid loss of the soil strength and stiffness occurs and the liquefied soil behaves as a pseudo-plastic fluid. 


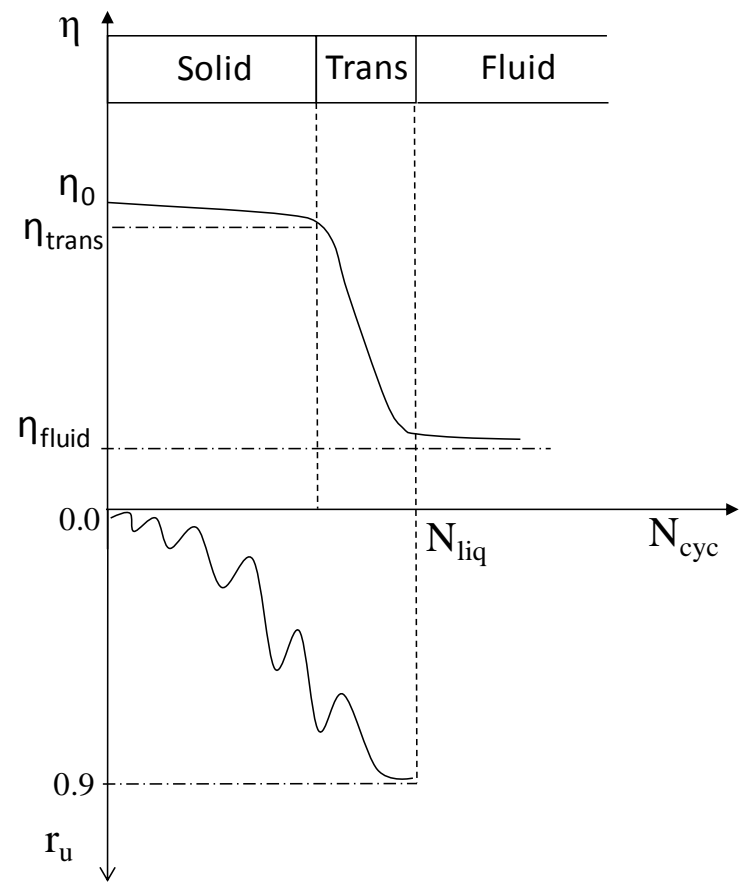

Figure 12. Link betweenthe decay low of the apparent viscosity $\left(\eta-\mathrm{N}_{\mathrm{cyc}}\right)$ and the pore pressure ratio build up ( $\left.\mathrm{r}_{\mathrm{u}}-\mathrm{N}_{\mathrm{cyc}}\right)$

In this conceptual model, the framework of soil mechanics can be adopted up to the transition phase $\left(\eta<\eta_{\text {trans }}\right)$ because the soil persists in its original solid state. In the transition phase ( $\left.\eta_{\text {trans }}<\eta<\eta_{\text {fluid }}\right)$ the change of state happens, and then the soil can be studied using a fluid mechanics approach.

In figure 13 the relationships between the normalized apparent viscosity $\left(\eta / \eta_{0}\right)$ and the pore pressure ratio $\left(r_{u}\right)$ obtained for all the analysed cyclic tests have been plotted. It can be noted that the liquefaction is completely developed $\left(r_{u}=0.90\right)$ when the viscosity is reduced by $85-95 \%$ compared to its initial value.

The average curves that best fit the experimental results are respectively:

$$
\begin{aligned}
\frac{\eta}{\eta_{0}} & =\frac{\left(1-r_{u}\right)^{3}}{\left(1-5 \cdot r_{u}\right)^{5}} \\
\frac{\eta}{\eta_{0}} & =\frac{\left(1-r_{u}\right)^{3}}{\left(1-3 \cdot r_{u}\right)^{6}}
\end{aligned}
$$

Sant'Agostino sand

Messina gravelly soil



(a)

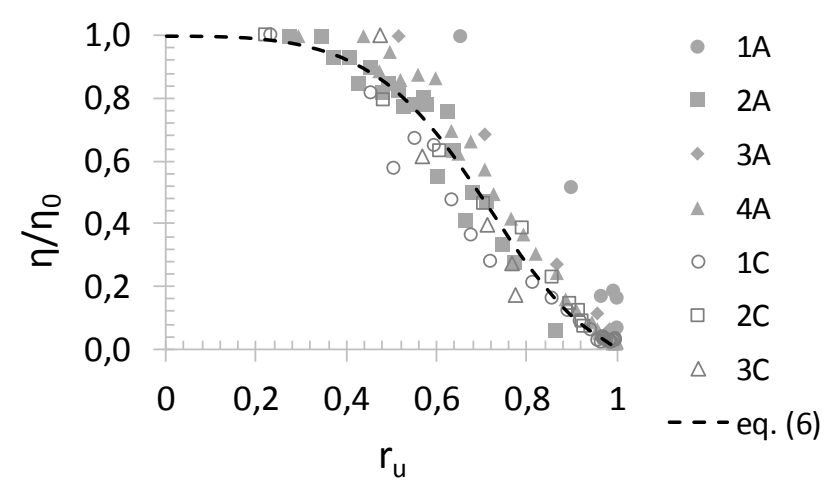

(b)

Figure 13. Relationship between $\eta$ and $r_{u}$ for SAS (a) and MES specimens (b)

The eqs. (5) and (6) may play an important role in the constitutive models of fluid mechanic to simulate the behaviour of liquefied soils. For a given soil $\left(D_{50}\right)$ the value of $\eta_{0}$ can be found via the relationship plotted in 
Fig. 8 and the relationship between $\eta$ and $r_{u}$ may be easily obtained via eqs. (5) and (6). Last, but not least, for $r_{u}=0.90$, the value of $\eta_{\text {fluid }}$ can be quantified. Further tests on soils with different grading need to be carried out to confirm the relationship of Fig. 8.

\section{CONCLUSIONS}

Some cyclic undrained triaxial tests have been processed in order to study the characteristic of granular materials under cyclic loading. Three different grain size distributions have been tested (from sandy to gravelly soils) and a large range of confining stresses $\left(50<\sigma{ }_{c}<400 \mathrm{kPa}\right)$ have been adopted in the experimental programme.

The experimental evidences confirm that the liquefaction phenomenon induces a change in the soil state, that switches from that of a solid to that of a viscous fluid: the apparent viscosity $(\eta)$ is a physically based parameter able to represent this change of state. For all the tests, the apparent viscosity decay laws $\left(\eta-\mathrm{N}_{\mathrm{cyc}}\right)$ have been obtained and the representative values of $\eta$ have been computed for the tested materials.

The laboratory data highlight the strong link between the apparent viscosity and pore pressure ratio build up $\left(\mathrm{r}_{\mathrm{u}}\right)$ measured during cyclic loading, highlighting the relevance of $\eta$ decay laws in constitutive modelling of soils that undergo liquefaction. Moreover, a simple approach to evaluate $\eta_{\text {fluid }}$ is shown too, starting from an experimental relationship between $\eta_{0}$ and $D_{50}$, even though it has to be confirmed by other tests carried out on several materials.

The experimental results presented in the paper confirm that the liquefied soils behave as shear thinning nonNewtonian fluid (pseudo-plastic fluid) and the useful relationships between $\eta$ and $\dot{\gamma}$ have also provided for three different tested materials in different state conditions, giving original data in terms of flow parameters (consistency coefficient and liquidity index) needed to calibrate flow constitutive models.

\section{ACKOWLEDGMENTS}

The authors greatly acknowledge prof. Alessandro Flora for his valuable suggestions and fruitful for the discussion on tests results and interpretation.

This work was carried out as part of the European project Horizon 2020 - Assessment and Mitigation of liquefaction potential across Europe: A holistic approach to protect structures infrastructures for improved resilience to earthquake - induced liquefaction disasters - "LIQUEFACT" (grant agreement No. 700748).

\section{REFERENCES}

Aydan, O. "Mechanical and numerical modelling of lateral spreading of liquefied soil." Proc. 1st Int Conf on Earth-Geo Eng, Tokyo. Vol. 881886. 1995.

Chen, Y.M., Liu, H.L., Zhou, Y.D. (2006). “Analysis on flow characteristics of liquefied and post-liquefied sand". Chinese Journal of Geotechnical Engineering 28(9): 1139-1143.

Chen, Y., \& Liu, H. (2011). Simplified method of flow deformation induced by liquefied sands. In Design, Construction, Rehabilitation, and Maintenance of Bridges (pp. 160-167).

Chen G., Zhou E., Wang Z., Wang B., Li X. (2016) Experimental study on fluid characteristics of medium dense saturated fine sand in pre- and post-liquefaction. Bulletin of Earthquake Engineering 14(8): 2185-2212.

Callisto L., Rampello S, Viaggiani G.M (2013). Soil structure interaction for the seismic design of the Messina Strait Bridge. Soil Dynamic and Earthquake Engineering 52(2013): 103-115.

Committee on Soil Dynamics of the Geotechnical Engineering Division (1978). "Definition of terms related to liquefaction". Journal of Geotechnical Engineering, 104(GT9), 1197-1120. 
Da Fonseca, A. Viana, M. Soares, and A. B. Fourie. "Cyclic DSS tests for the evaluation of stress densification effects in liquefaction assessment." Soil Dynamics and Earthquake Engineering 75 (2015): 98-111.

Finn, W. D., Dennison J. Pickering, and Peter L. Bransby. "Sand liquefaction in triaxial and simple shear tests." Journal of Soil Mechanics \& Foundations Div (1971).

Flora, A., S. Lirer, and F. Silvestri. "Undrained cyclic resistance of undisturbed gravelly soils." Soil Dynamics and Earthquake Engineering 43 (2012): 366-379.

Flora, A., \&Lirer, S. (2013). Small strain shear modulus of undisturbed gravelly soils during undrained cyclic triaxial tests. Geotechnical and Geological Engineering, 31(4), 1107-1122.

Hadush, S., A. Yashima, and R. Uzuoka. "Importance of viscous fluid characteristics in liquefaction induced lateral spreading analysis." Computers and Geotechnics 27.3 (2000): 199-224.

Hamada, M., \& Wakamatsu, K. (1998). A study on ground displacement caused by soil liquefaction. Proc. JpnSoc Civil Eng, 1998(596), 189-208.

Hamada, M. (2000). Performances of foundations against liquefaction-induced permanent ground displacements. In Proc., 12th World Conf. on Earthquake Engineering (pp. 1754-1761).

Huang, Y. T., Huang, A. B., Kuo, Y. C., \& Tsai, M. D. (2004). A laboratory study on the undrained strength of a silty sand from Central Western Taiwan. Soil Dynamics and Earthquake Engineering, 24(9-10), 733-743.

Hwang, J. I., Kim, C. Y., Chung, C. K., \& Kim, M. M. (2006). Viscous fluid characteristics of liquefied soils and behavior of piles subjected to flow of liquefied soils. Soil Dynamics and Earthquake Engineering, 26(2-4), 313-323.

Ishihara, Kenji, and Fumio Yamazaki. "Cyclic simple shear tests on saturated sand in multi-directional loading." Soils and Foundations 20.1 (1980): 45-59.

Ishihara, Kenji. "Liquefaction and flow failure during earthquakes." Geotechnique 43.3 (1993): 351-451.

Jefferies M.G., Been K., 2006. Soil liquefaction- a critical state approach. Taylor and Francis Ed.

Li Y., Yang Y., Yu H-S., Roberts G. (2016). Undraind soil behaviour under bidirectional shear. Proc. $4^{\text {th }}$ GeoChina International conference, July 2016 Shandong, China.

Kammerer A., Wu J., Riemer M., Pestana J, Seed R. (2004). Shear strain development in liquefiable soil under bi-directional loading conditions. Proc. $13^{\text {th }}$ World Conference on earthquake Engineering, Vancouver (Canada).

Mele L., Tan Tian J., Lirer S., Flora A., Koseki J. (2018). Liquefaction resistance of unsaturated sands: experimental evidence and theoretical interpretation. Géotechnique. DOI: 10.1680/jgeot.18.p.042.

Mele L., Lirer S., Flora A. (2019). The effect of confinement in liquefaction tests carried out in a cyclic simple shear apparatus. $7^{\text {th }}$ International Symposium on Deformation Characteristics of Geomaterials, Glasgow (Scotland), June 2019.

M. L. Silver, F. Tatsuoka, A. Phukunhaphan and A.S. Avramidis. Cyclic undrained strength of sand by triaxial test and simple shear test. Proc., $7^{\text {th }}$ World Conference on Earthquake Engineering, 3: 281-288 (1980).

Tanaka, Y., KOKUSHO, T., YOSHIDA, Y., \& KUDO, K. (1991). A method for evaluating membrane compliance and system compliance in undrained cyclic shear tests. Soils and foundations, 31(3), 30-42.

Uzuoka, R., Yashima, A., Kawakami, T., \& Konrad, J. M. (1998). Fluid dynamics based prediction of liquefaction induced lateral spreading. Computers and Geotechnics, 22(3-4), 243-282.

Verdugo, Ramon, and Kenji Ishihara. "The steady state of sandy soils." Soils and foundations 36.2 (1996): 8191. 
Wu J., Kammerer, A. M., Riemer, M. F., Seed, R. B., \& Pestana, J. M. (2004, August). Laboratory study of liquefaction triggering criteria. In 13th world conference on earthquake engineering, Vancouver, BC, Canada, Paper (No. 2580).

Yamada, Yasuo, and Kenji Ishihara. "Undrained deformation characteristics of sand in multi-directional shear." Soils and Foundations 23.1 (1983): 61-79.

Zhou, E. Q., Lv, C., Wang, Z. H., \& Chen, G. X. (2014). Fluid Characteristic of Saturated Sands under Cyclic Loading. In Advances in Soil Dynamics and Foundation Engineering (pp. 178-186). 